\title{
Agustín y agustinismo
}

Los AGUSTINISMos.

El segundo centenario de la muerte de Juan Lorenzo Berti, y el significado que este gran teólogo tiene para la Escuela Agustiniana, la Cenicienta de la Teología, nos invita a refrescar un poco la memoria y a hacer algunas reflexiones sobre la relación de San Agustín con sus admiradores y lectores. No vamos a volver sobre las polémicas pasadas, sino más bien a meditar en el sentido del mismo Agustín para la cultura teológica de la actualidad, o si se quiere, en las posibilidades de un "agustinismo" acomodado a los tiempos en que vivimos. De este modo la meditación sobre los agustinismos históricos lleva una finalidad, que se desprende del significado de Berti: no se debe privar a la Iglesia de ninguna fuente de espiritualidad y de energía ${ }^{1}$.

Agustín lanzó su mensaje en medio de un mundo decadente ${ }^{2}$. Su muerte coincidió con el nacimiento de Europa, amalgama de la cultura clásica con la cultura nórdica dentro del Cristianismo. De este modo se ha podido presentar a Agustín como "Genio" de Europa ${ }^{3}$. En su nombre se realizó la nueva síntesis: los dirigentes del nuevo mundo, Gregorio Magno, Isidoro, Casiodoro, Boecio, Cesáreo de Arlés, Pomerio, etc., apenas tendrían valor ni sentido, si se les priva de su fundamento, que es Agustín. Surge así espontánea la tentación de llamar a Agustín "Padre de la Edad Media" y hasta podría llegarse a pensar que Europa,

1 A. TRapé, "Berti, Giovanni Lorenzo": Enciclopedia Cattolica, II, 1469 1470. B. VAN LUIJK, "Gianlorenzo Berti, Agostiniano (1696-1766)": Rivista di Storia della Chiesa in Italia, 14 (1960) 235-262, 383-407.

2 R. EuCKEN, Die Lebensanschauungen der grossen Denker, 2. ${ }^{\mathrm{a}}$ ed., Berlín 1950, 217. En casi todos sus libros insiste Eucken en poner como ejemplo a Agustín, por haber infundido un nuevo espíritu y haber hallado una nueva fuente de vida para una cultura agonizante.

3 E. Przywara, Augustinus. Die Gestalt als Gefüge, Leipzig 1934, 17. 158.

4 J. Hessen, Platonismus und Prophetismus, 2." ed., München-Basel 1955, 
no sólo en la Edad Media, sino también en la Moderna, es un "agustinismo" 5 .

Por lo que toca a la Edad Media, el problema es harto complejo. La cultura nórdica, que podemos llamar "feudalismo", no era una simple organización social o política, sino que era un nuevo modo de ver el mundo, el hombre, la sociedad, la religión, el trabajo, el Estado, la Iglesia, la autoridad, la jerarquía, la organización, la técnica, la oración, la virtud, la lealtad, todo: sus fuentes de inspiración eran autónomas y nada tenían que ver con San Agustín; más bien se oponían al "intimismo" o "espiritualismo" de Agustín. Por otra parte, pronto comenzaron a aparecer en Europa otras influencias, que más bien rivalizan con Agustín: Boecio, Escoto Eriugena, el Seudodionisio, Aristóteles y el mismo Platón ${ }^{6}$.

Podríamos decir que la época inmediata a la muerte de Agustín es un agustinismo en cuanto que todos los pensadores se inspiran en el Santo. Pero en realidad el término "agustinismo" reclama una cierta contraposición, un cierto antagonismo. Por eso se habla de "agustinismo" más bien cuando el movimiento provocado por las "Ideas gregorianas", opone a la herencia de los carolingios un espíritu de interioridad y de austeridad, que se va concretando en la institución de los "canónigos regulares" y que triunfa en los "canónigos de San Agustín". Su triunfo pleno se logra en la Escuela de San Víctor, ya que aquí tenemos una fuerte oposición, no sólo al imperio Carolingio, sino también al imperio de la Dialéctica, que se venía implantando en Europa desde Boecio. Del mismo modo la Escuela Franciscana se constituyó en "agustinismo", en oposición al imperio de Aristóteles. En suma, los "agustinismos" surgen en realidad por contraposición a un ambiente, a una situación, en la que el espíritu de Agustín se siente incómodo: esto da al "agustinismo" un cierto aire revolucionario ?.

5 Tal es el sentido del libro de Przywara antes citado: la historia de la cultura europea es una sucesión y lucha de agustinismos.

6 A. DEMPF, Metaphysik des Mittelalters, Berlín 1930.

7 Przywara, en el libro citado, nos ofrece varias otras formas de "agustinismos" antiguos y modernos, y en todos aparece siempre ese aire de oposición a un ambiente. El tema debiera, sin embargo, estudiarse más detenidamente, ya que con el término "agustinismo" se designan cosas tan variadas como una teoría política, una doctrina filosófica o teológica, una relación entre el alma y el cuerpo, entre el alma y la verdad, entre el alma y Dios, entre la libertad y la gracia, entre la gracia y la naturaleza, etc., etc. Cfr. A. Portalie, "Augustinisme": DTC. I, 2.485-2.501 y 2.501-2.561. Hay una larga serie de tópicos ya consagrados que siembran la confusión. 
De este modo el "agustinismo" se presenta en el organismo eclesiástico como una suerte de fiebre, para anunciar la enfermedad, la alteración de humores, la necesidad de reacción. Subsiste siempre, sin embargo, el problema básico: ¿Son realmente "agustinianos" esos "agustinismos", o son más bien "interpretaciones" aproximadas de Agustín? Se nos presenta así un estudio de semejanzas y diferencias, que no puede pasarse por alto, cuando se ve el problema desde el mismo San Agustín. Si pensamos, por ejemplo, en los agustinismos de la Edad Media, se destacan con demasiada violencia las diferencias: ni Agustín pudo soñar jamás esa Edad Media, ni el hombre medieval logró nunca vivir el Imperio Romano. Aquellos titanes, que se llamaron maniqueísmo, estoicismo, epicureísmo, escepticismo, neoplatonismo, donatismo, pelagianismo, e incluso paganismo, que fueron forjando el espíritu de Agustín a golpe de maza en la vieja fragua del metafísico Vulcano, no tenían vigencia alguna en la Edad Media; se los conocía de oídas, pero no se combatía frente a ellos. Lo que Europa hiciera con los materiales de Agustín era obra de ella, no de él. Agustín no es un hombre medieval: es un antiguo, consumación y plenitud de la Antigüedad, "el último y supremo pensador, el Práctico espiritual, el Tribuno Popular de la Iglesia" 8 .

Podría estudiarse el caso de San Buenaventura como caso típico y elocuente, viendo sus relaciones con Agustín por un lado y con Aristóteles por otro. Estas son tales que con razón se ha dicho que el término "agustinismo" es un común denominador de todos los sincretismos medievales, incluído el de Santo Tomás de Aquino ${ }^{9}$.

Es un hecho que el triunfo rotundo de Aristóteles en la Universidad europea condicionó en adelante todos los agustinismos. Podríamos incluso pensar que ese triunfo convierte el agustinismo en una corriente "subterránea", que va dando vida y fecundidad al pensamiento europeo, mientras el aristotelismo envejece y se va convirtiendo en un disco

8 E. Troelstsch, Augustin, die christliche Antike und das Mittelalter, München-Berlín 1915, 4, 7 y 8. E. EloRduY, Sto. Tomás y el Tradicionalismo medieval: "la oposición entre el tradicionalismo medieval y el patrístico no es oposición entre las opiniones personales de los dos grandes doctores, Agustín y To más. La Edad Media no podía comprender la época patrística..." (p. 65).

9 J. GUY BougERoL, Introduction a l'Etude de S. Bonaventure, París-Tour. nai 1951, 70. L. MEIER, "Bonaventuras Selbstzeugnis über seinen Augustinismus": Francisk. Studien 17 (1930) 342-355; J. DE CHELLINCK, Aus der Geisteswelt des Mittelalters, Münster 1935, 403-426; M.-D. CHEnU, La Théologie comme science au XIII siécle, 3. ed., París 1957; E. GrLson, La philosophie au Moyen Age, 2. ${ }^{\mathrm{a}}$ ed., París 1934. 
gastado ${ }^{10}$. El agustinismo continúa, pues, cumpliendo su misión y no faltan pensadores que nos presentan el cartesianismo, el protestantismo y todos los ismos modernos como formas de agustinismo ${ }^{11}$. Las polémicas modernas en torno a este tema merecen un estudio ponderado, ya que algo quieren significar. ¿Por qué un Hessen y un Przywara, que se presentan como rivales y extremos polares dentro del Catolicismo, desean, sin embargo, un agustinismo, hasta el punto de que no se sabe quién de los dos lo desea con mayor vehemencia? Hessen defiende una "intuición", una "mística" y para ello necesita un agustinismo; Przywara combate a Hessen hasta desarraigarlo del todo y necesita a su vez un agustinismo ${ }^{12}$. ¿Qué es lo que acontece aquí?

Aunque estos temas sean interesantes, la ocasión de recordar al teólogo Berti nos obliga a circunscribirnos a un "agustinismo" especial. En el año 1256 aparece la llamada Orden de Ermitaños de San Agustín, dentro de la cual se cultiva el pensamiento de que el mismo San Agustín ha sido Fundador de la misma. Dejando a un lado esa ilusión (toda la Historia de la Iglesia y del mundo está llena de tales ilusiones), interesa mucho apuntar esa convicción obstinada. Gracias a ella, los "agustinos" comenzaron al momento una pugna con los Canónigos de San Agustín para conquistar un derecho de preferencia. Los teólogos de esta Orden comenzaron a considerar las obras de San Agustín como un patrimonio

10 J. Hessen, Die Weltanschauung des Thomas von Aquin, Stuttgart 1926. Las fórmulas exageradas de este libro produjeron disgusto en muchos ambientes católicos y crearon a su autor graves dificultades. Cfr. B. Franzelin, Zeitschr. f. Kathol. Theologie 51 (1927) 256 ss.

11 A. INAUEN, "Augustin und Augustinismus": Zeitschr. f. Kathol. Theologie 48 (1924) 265 ss.; B. FRANZELIN "Augustinus und seine Bedeutung für die Gegenwart": Zeitschr. f. Kathol. Theologie 48 (1924) 603 ss. Estos dos autores combaten a Hessen. La fórmula "Agustín y la actualidad" es ya un tópico tan gastado que produce enfado. Pero demuestra algo muy importante: todos estiman que Agustín tiene siempre un mensaje para la actualidad. En la polémica Hessen-Franzelin, como en la polémica Hessen-Przywara, a la que nos referiremos en seguida, ambos contendientes están de acuerdo en la necesidad de un agustinismo militante.

12 Przywara combate a Hessen negando hasta la posibilidad de la mística y de la "intuición": E. PrzYwara, Religionsbegrundung. Max Scheler-Newman, Freiburg i. Br. 1923; ID., Gottgeheimnis der Welt. Drei Vorträge..., München 1926; ID., "Religionsphilosophie Katholischer Theologie": Handbuch der Philosophie, München-Berlín 1927. Pero, al mismo tiempo, Przywara hace propaganda de agustinismo y hasta trata de imponer el mito del agustinismo: E. PRZYWARA, "Das augustinische Geistesmotiv und die Krise der Gegenwart": Kantstudien 35 (1930) 252-272; ID., Augustinus. Die Gestalt als Gefüge, Leipzig 1934. Estas polémicas católicas sugieren: frente al Catolicismo hay otros movimientos religiosos, que hay que tener en cuenta; casi siempre, esta discusión entre católicos es cuestión de palabras, pues ni Hessen ni Przywara definieron la intuición y hablaban de cosas diferentes; el aristotelismo es bueno para sistematizar (formalismo), no para buscar la verdad. 
familiar y nació una Escuela Agustiniana de Teología, que se llamó "egidiana", por haber sido Egidio Romano el organizador y primer representante de la misma. De este modo se produce un fenómeno singular: aparece una escuela que tiene características comunes fuertes, de manera que se puede llamar una "escuela": sin embargo, dentro de ella unos son "tomistas", otros son "franciscanos" y otros son "libres"; por otra parte, dentro de una libertad, que pertenece a los rasgos de la escuela, cada autor interpreta a San Agustín a su manera, libremente. Dentro de los otros agustinismos, que actúan incesantemente, pero que pertenecen a la corriente subterránea, de que habló Hessen, este agustinismo militante defiende expresa y formalmente el espíritu y el sistema de San Agustín. El último gran representante de esta escuela, Cenicienta de la Teología católica, fue el discutido Juan Lorenzo Berti ${ }^{13}$.

Esos rasgos a que antes hemos aludido anuncian ya las enormes dificultades con que tropieza quien quiera reducir a un sistema lógico y ordenado la exhuberancia y libertad de esta escuela. Aparte la distinción en cuatro ramas, capitaneadas respectivamente por Egidio Romano y Gregorio de Rímini, o constituídas por la llamada "escuela de Salamanca" y la "escuela italiana", han tratado algunos de precisar un poco los rasgos generales de la escuela ${ }^{14}$. El Rvmo. Trapé ha reducido a tres los rasgos principales: a) primado del amor; b) primado de la gracia; c) primado de Jesucristo ${ }^{15}$.

Bien se ve que tales rasgos no son tesis concretas, sino más bien un espíritu que apunta a un sistema. Pero por eso mismo son más "agustinianos", más profundos y radicales, más importantes. Suponiendo, pues, que efectivamente estos rasgos sean característicos de la escuela agustiniana de teología, se impone una reflexión muy seria: ¿son también "agustinianos", de San Agustín? Este es, a mi juicio, el problema que suscita al centenario de Berti. Sería de desear una restauración de la Escuela Agustiniana, ya que no se puede privar a la Iglesia

13. En otro número de esta misma Revista daremos la Bibliografía General de la llamada Escuela Agustiniana de Teología. Cfr. D. GuTírrrez, "La Bibliografía del último decenio en torno a la Escolástica Agustiniana": La Ciudad de Dios 156 (1944) 17-46.

14 D. GuTifrrez, "Notitia historica antiquae Scholae Aegidianae": Analecta Augustiniana 18 (1941) 39-67; ID.» "Del origen y carácter de la escuela teológica hispano-agustiniana en los siglos XVI y XVII": La Ciudad de Dios 153 (1941) 227-255. Los dos hermanos Ursicino Domínguez y Eloy Domínguez han publicado interesantes artículos, que pueden verse en la Bibliografía.

15 A. Trapé, "Scuola Teologica e spiritualitá nell'Ordine Agostiniano": Augustinus, vitae spiritualis Magister, II, 12; A. TurRaDo, "Notas sobre la espiritualidad agustiniana": La Ciudad de Dios 169 (1956) 686-716. 
de una fuente de vida, pero sería de desear también que en lugar de una libertad discutible, se impusiera la crítica histórica de manera que una Escuela de San Agustín refleje realmente a Agustín ${ }^{16}$.

EL espíritu y el SISTEMA.

Tratándose de San Agustín, es necesario comenzar por aquí: Agustín es, ante todo, un "espíritu", una postura personal. Y puesto que Agustín mismo insistió en su fórmula Deum et animan scire cupio; Domine, noverim me, noverim $T e$, es preciso, ante todo, dejar consignado que una Escuela de San Agustín no puede ser nunca una escuela de especulación, sino una Escuela de posturas integrales y personales. Quien separa la vida de la especulación, o la teoría de la práctica, está ya animado por un espíritu diferente, no por aquel espíritu de "convertido" que obligó a Agustín a pensar y a pensar de un determinado modo y en una determinada dirección. Es, pues, obvio que en una Escuela Agustiniana, la especulación es vida, postura, práctica, expresión o revelación de una actitud ante Dios.

El punto de partida será siempre el escepticismo. Agustín es, ante todo y sobre todo, un hombre llegado del escepticismo, esto es, un "náufrago". Tiene que pensar necesariamente con un alma de náufrago ${ }^{17}$. Pero, al mismo tiempo, el punto de llegada será siempre la Biblia. Agustín es, ante todo y sobre todo, un hombre que descubrió la Biblia y se entregó a ella atado de pies y manos ${ }^{18}$.

Suele con frecuencia definirse la postura central de Agustín como "teocéntrica"; nosotros rechazamos esa tesis, que es ambigua y falsa. La postura fundamental de Agustín es "antropocéntrica": un escéptico se preocupa sobre todo por la ratio, por la relación de la ratio con la veritas (Noverim me, noverim $T e)^{19}$. Aunque el náufrago se vea

16 Esto sea dicho en general y mirando a la actual crítica histórica: es sabido que cada autor defiende que su interpretación de San Agustín es auténtica. Hoy, sin embargo, hay ya cosas indiscutibles, y sobre otras conviene discu. tir hasta que se haga claridad, como lo hacemos nosotros aquí.

17 Cfr. H. HARTMANN, Gewissheit und Wahrheit, Halle 1927.

18 Nadie ha intentado aún un estudio comparativo del espíritu de la Biblia y del anciano Agustín y esta es la causa de tantas confusiones en la explicación de la polémica pelagiana.

19i Cfr. A. DEMPF, Metaphysik des Mittelalters, Berlín 1930. En las páginas 15-31 presenta a Agustín como creador de la metafísica medieval, primer expositor formal del acto creador, de la metafísica del alma, y aun de la metafísica cristiana del cosmos. Pero, por desgracia, estima que eso es teocentrismo; 
ya asentado en un paraíso y viva agradecido a quien le sacó a viva fuerza de entre el fragor del oleaje, siente todavía en sus oídos el rumor de las olas.

Finalmente, el espíritu de Agustín es dialéctico, sistemático por esencia. Por eso es suficiente dar un punto de partida y un camino. Lo demás, lo creará por sí mismo ese espíritu sistemático, que nunca pierde de vista sus principios y fundamentos trascendentes ${ }^{20}$.

En Agustín hay un sistema, harto rígido, pero interno. Las "indeterminaciones" son propias de sus comentaristas, pero no de él. La razón de esto es que siempre relaciona cada tesis con el último principio y fundamento, y de ese modo todas las cosas tienen sentido y valor desde el fundamento. Más difícil es explicar el "sistema" en los agustinismos, ya que los escolásticos son siempre sincretistas ${ }^{21}$.

Supuesto el antropocentrismo de Agustín, el sistema será "existencial" en cierto modo. No queremos decir que el "ser" se identifique con el tiempo como en Heidegger, o que el ser temporal sea producto del idealismo, como en el mismo Heidegger. Pero, si suprimimos esas dos apostillas heideggerianas, Agustín reconoce a las criaturas de Dios todos los derechos del ser temporal y todas las imágenes y semejanzas del ser eterno. El sistema de Agustín se refiere, pues, siempre al Dios personal y creador, libre y trascendente, al mundo creado, contingente y evanescente, y al hombre de la calle, histórico y temporal. El sistema agustinismo es, pues, imperial, sin naturalismo, sin forzosidad, voluntarista. Es además, "histórico" (pasado, presente y futuro). Esto demuestra, al parecer, que Agustín no ha dejado nunca de ser un hombre religioso, aun dentro de sus ideologías filosóficas. Por lo tanto, el platonismo, que fue para él una "praeparatio evangelica", le planteó al mismo tiempo un conflicto radical.

Ese conflicto podría expresarse así: Platón aprovechó la religión

además, reprocha a Diltey el haber presentado a Agustín como "antropocentrista", acusándole de anacronismo, como si la preocupación por la ratio o por el ego, fuese subjetivismo del siglo XIX.

20 La Edad Media continuó por su cuenta la obra de Agustín, pero participó de su dialéctica. No se debe oponer "platonismo cristiano" a "aristotelismo cristiano", ya que entre ambos las diferencias son superficiales y accidentales. La diferencia real se produce entre "platonismo" y "profetismo". Cfr. J. Hessen, Griechische oder biblische Theologie, Leipzig 1956, 123 y 185.

21 Hay que tener en cuenta, sin embargo, la evolución ideológica del mismo Agustín y las exigencias del sistema, siempre que se modifiquen los presupuestos. Cfr. G. NyGREN, Das Prädestinationsproblem in der Theologie Augustins, Göttingen 1956, 176-195. 
de misterios, pero convirtiendo su contenido en filosofía, mientras que Agustín aprovecha la filosofía para convertirla en religión. Su antropocentrismo radical, que apuntaba a una soteriología, no se reducía al carácter socrático: no es el hombre para el cosmos, sino el cosmos para el hombre. Es algo más: el espíritu está por encima del cosmos, exento de las leyes del cosmos: es una luz misteriosa que, según los mitos y las religiones, viene de Dios de un modo especial. Por ende, dentro del Cristianismo, Agustín encuentra en la Biblia los elementos apropiados para organizar su sistema existencial, en oposición a un sistema esencial o estrictamente filosófico. De ahí que Agustín en sus primeros años platónioos vivió como fuera de sí, esperando vanamente la visión extática y mística de Dios. Ese Agustín es un compás de espera.

Pero con esto no pretendemos insinuar que el platonismo fuese en Agustín un cuerpo extraño, un sarampión provisional. El escepticismo implica un anhelo de absoluto y Agustín arrastraba consigo esa lesión cardíaca, aunque le diera carácter religioso, más bien que filosófico. Leyó sí a los platónicos con ojos cristianos, pero leyó también la Biblia con un corazón sediento de lo absoluto, de lo eterno, de lo intemporal, de lo exento ${ }^{22}$.

Lo que de aquí se deduce no es una doble personalidad, sino una tensión. La esencia de un agustinismo consistirá siempre en una tensión entre la razón y la verdad, entre el tiempo y la eternidad, entre el alma y Dios. Así el sistema agustiniano se debatirá siempre dentro de una dialéctica que es una "relación", caminará siempre en busca de un principio y fundamento y estribará siempre en ese principio y fundamento. La pretensión agustiniana de reunir la filosofía con la teología, la religión natural con la revelada, la naturaleza con la gracia y así sucesivamente tendrá luego la contrapartida de verse obligada a ir separando, una vez que comienzan a descubrirse las falsas promesas del platonismo o del naturalismo. El acento cae del lado del tiempo y la eternidad queda relegada a la lejanía. Al abismarse en el espíritu de la Biblia, Agustín condiciona la filosofía a la Biblia.

Pelagio obligó a separar la naturaleza de la gracia. El Cardenal Newman se hizo propagandista del "unitarismo", pero muchos alegaron contra él las fórmulas del Concilio Lateranense IV, que parecen poner como base la analogía entis. Agustín dice que Adán en el paraíso era 
un Dios de gracia (De Gen. c. Manich., II, 22, 33, PL. 34, 213), y que nosotros mismos somos Dios de gracia (Serm. 16, 4, PL. 38, Ego dixi: dii estis...).

Ya se ve cuánto se equivocan los que nos presentan a un Agustín platónico, idealista, sediento de una pureza angélica y química, que considera el mundo real como una vileza ${ }^{23}$. Por el contrario, Agustín acusa a los idealistas y platonizantes pelagianos, porque quieren hacernos creer que vivimos en un mundo "puro". No es que a Agustín le parezca vil el mundo, es que el mundo lleno de maldad es la única realidad con que hay que contar, sin platonizarla. El mal del mundo es el mejor bien que tenemos. Pero tampoco hay que exagerar en sentido contrario, como si Agustín fuese un positivista moderno, preocupado por sustituir el concepto de "participación" por el de "causalidad" ${ }^{24}$ o de imponer a la metafísica los métodos de la experiencia interior ${ }^{25}$.

Un sistema agustiniano no necesita estar plenamente desarrollado. Ningún sistema lo está. Si está animado por el auténtico espíritu, si admite el principio y fundamento, en lugar de apoyarse en el cosmos, o en la experiencia interna, si reconoce los principios elementales para la Noética, Física y Etica (Filosofía) o para la Historia de la salvación (Teología), todo lo demás será tarea de la Dialéctica. Agustín pudo hacer frente a problemas nuevos y graves; él mismo afirmó que tales problemas nuevos y graves tienen una solución fácil desde un sistema firme ${ }^{26}$.

Algunos autores tratan de presentar como esencia del agustinismo un "romanticismo". Tienen algún fundamento en el "inquietum cor" de Agustín, pero ya hemos hecho ver que la inquietud agustiniana brota

23 Así lo estima erróneamente B. LEGEWIE, Augustinus. Eine Psychographie, Bonn 1925, 123-126.

24 Tal es la equivocación de A. DEMPF, Die Hauptform mittelalterlicher Weltanschauung, München 1925, 116 y 156. Es curiosa esta insistencia en convencernos de que fue Santo Tomás quien impuso la preponderancia de las "causas segundas", como si eso fuese problema alguno. Hay que advertir que muchos de los "agustinistas" eran tomistas rígidos e incluso exagerados: pensemos, por ejemplo, en el mismo Egidio Romano, a quien muchos atribuyen las tesis tomistas, o en Gerardo de Sena.

25 Equivocación de F. SeIfert, Psychologie. Metaphysik der Seele, 31 ss.

26 Da igitur qui cito videat..., Epist. 118, 3, 14 ss., PL. 33, 438. Agustín pide que le den un hombre que vea los fundamentos y antecedentes $\mathrm{y}$ hará ver cómo llega por sí solo a las consecuencias. Es claro que el platonismo, con la prueba de la experiencia del Menón y con el método mayéutico hace ver a Agustín que la labor del hombre intelectual es llegar a los principios y fundamentos; todo lo demás es pura dialéctica, $y$ por eso el "sistema" es un problema de dialéctica simplemente. 
àel mismo escepticismo, del sentido soteriológico del espíritu y del sistema, sobre todo teniendo en cuenta la tensión que ya apuntamos entre el tiempo y la eternidad. Si hemos de aceptar como rasgos fundamentales del romanticismo el ocasionalismo, el esteticismo y el subjetivismo ${ }^{27}$, es claro que ni Agustín ni el agustinismo son románticos. Aceptan, sin embargo, la realidad palmaria: vivimos en un orden alterado, en un desorden. Si durante algún tiempo trató de volatilizar el mal del mundo con un optimismo realmente platónico, pronto hubo de comprobar que los hombres viven aquí en una "mala" situación, víctimas de un "mal" o pecado, principio activo y siniestro, que produce el continuo desorden. $Y$ este sentido del mal es uno de los rasgos de todo agustinismo.

El "inconsciente" ha creado siempre un problema para el agustinismo. Agustín no identifica la razón con la consciencia. Considera a ésta como un fenómeno de la atención y a aquélla como propiedad del espíritu. En cambio el sentido que tomó la Dialéctica medieval, obligó a considerar las potencias del alma como conscientes. Es verdad que se hablaba no poco de sindéresis o Syntéresis, con un vocablo que Alejandro de Hales tomó de San Jerónimo. Pero la sindéresis quedaba reducida, no sabemos por qué, al terreno moral, ya que la moral era un "feudo agustiniano"; y además esa sindéresis tenía que recibir de fuera su contenido, su sentido y su valor. De ese modo era casi imposible llegar a comprender esa "memoria Dei" de que nos habla Agustín, o bien porque se la interpretaba un poco al estilo aristotélico, o bien porque se la temía y se la pasaba por alto ${ }^{28}$.

Pero se trata aquí de algo, sin lo cual no puede subsistir ningún agustinismo, ya que es el verdadero punto de partida. Dentro del corazón humano se ocultan algunos tesoros, informes, sucios, medio enterrados, restos de un naufragio arrojados a una playa oscura. Pero

27 C. Schmiтt, Politische Romantik, München 1925, 135 ss. De aquí arranca el constructivismo, un tanto convencional, de Przywara. Cfr. E. Przywara, Ringen der Gegenwart, 218-221.

28 Cfr. F. NITZSCH, Über die Entstehung der scholastischen Lehre von der. Syntheresis (Jahrbücher f. protest. Theologie), Leipzig 1879, 492-507. San Jerónimo había escrito syneídesis y no syntéresis. Alejandro de Hales se mantenia en un espíritu rigurosamente agustiniano, en una memoria Dei: videtur ouod synderesis sit quodam conjunctum omnibus viribus superioribus animae. Cum enim homo per peccatum corruptus fuit in naturalibus, non adeo fuit corruptus ouod nihil remaneret intearum... Synderesis est rectitudo manens in sinaulis viribus, concordans rectitudini primae. AlEJANDRo DE H., Summ. Theol. II, a. 89. Cfr. S. Tomás, S. Th. I, q. 79, 12. S. Buenaventura, Brevil. II, 11. Un buen estudio de este punto en A. ScHNEmER, Die Psycholoaie Alberts des Grossen (Beiträge z. Geschichte d. Mittelalters), Münster 1903, Band 4. Heft 5 . 
no es lo mismo tener que crearlo todo, al estilo robinsoniano, que el tener ya de antemano algunos tesoros con que contar. El hombre medieval retenía la autoridad de Agustín en la Teología y en la Etica, ya que la Etica a Nicómaco se convertía en un donaire. Pero eso no era suficiente para abarcar todo el sistema de Agustín. El problema central, que es la relación del espíritu con Dios, es muy diferente si partimos del hecho de un naufragio, o si partimos de un Robinsón indígena y autónomo, sin historia y sin preocupaciones ${ }^{29}$.

De todos modos, el problema del agustinismo parece muy diferente en la época moderna de lo que fue en la época antigua y casi hasta nuestros días. $\mathrm{El}$ hombre medieval estaba demasiado recluído en la tradición uniforme de sus "Maestros" y no es extraño que muchos autores se muestren escépticos frente al agustinismo "técnico", aunque sean excesivamente complacientes frente a un agustinismo amplio o "escolástico" "30. Los escolásticos hablaban de un deseo natural, y sin embargo se referían a un deseo que se hacía consciente en actos formales del entendimiento o de la voluntad. Aún los últimos representantes destacados de la "Escuela Agustiniana" no penetraban bastante, por faltarles un concepto claro del inconsciente ${ }^{31}$. Hoy, en cambio, tenemos el camino despejado y podemos conocer hasta el fondo el pensamiento de Agustín. Claro está que nos cuidaremos mucho de confundir el "insconsciente

29. P. Vignaux, Il pensiero nel Medievo, Brescia 1947.

30 Conocida es la complacencia con que el P. Boyer interpreta escolásticamente a San Agustín. Sin embargo, sobre el agustinismo técnico llega a decir: "Las tesis del agustinismo medieval, o no son agustinianas, o tienen en San Agustín tan sólo un vago fundamento. El agustinismo de los jansenistas del seiscien. tos se pronunciaba a veces contra la letra y con mayor frecuencia contra el espíritu del Doctor de la Gracia. Los ontólogos del ochocientos se llamaban discí. pulos de San Agustín presentando una interpretación que hoy es rechazada por casi todos. El historicismo de estos últimos años... nos ha impedido ver la coherencia del pensamiento agustiniano y su permanencia en la tradición filosófica cristiana”. C. BOYER, Sant' Agostino Filosofo, 2." ed., Bologna 1965, 10. Cfr. H.-X. ARQuILIERe, "Sur la Formation de la théocratie Pontificale": Melanges Ferd. Lot, París 1925; G. CoMBes, La Doctrine Politique de S. Augustin, París 1927, 411-200; G. THERX, "L'Augustinisme médieval et l'unité de forme sustan. tielle": Analecta Hebdomadae August. Thomistae, Roma 1931, 140-200; R. CARTON, "Le Christianisme et l'Augustinisme de Boéce": Melanges Augustin., París 1931, 243-339; Fr. KLINGNER, Römische Geisteswelt, Leipzig 1943.

${ }_{31}$ En este mismo número de la Revista va incluido un artículo sobre el deseo natural de ver a Dios, según Tomás de Argentina o Estrasburgo. Cfr. J. MoRÁN, "Juan Lorenzo Berti y su interpretación de la Memoria Dei agustiniana": La Ciudad de Dios 176 (1963) 235 ss. Ya se hacen algunos ensayos de adaptación de la filosofía escolástica a San Agustín, aunque el medio de referencia haya sido tomado de Kant. Cfr. J. MARECHAL, Le point de Départ de la Métaphysique, II, 4. ${ }^{a}$ ed., París 1965, 56 ss; H. HoLz, Transzendentalphilosophie und Metaphysik, Mainz 1966. 138 ss. 
científico" de Freud con el "inconsciente filosófico" de Agustín; pero ambos inconscientes se completan muy bien: Agustín ha construído una filosofía dispuesta ya para recibir la superestructura científica del psicoanálisis. Ese es uno de sus mayores atractivos y de sus ventajas. La crítica de Sartre al psicoanálisis es en gran parte tan sólo una cuestión de palabras.

\section{Primado del amor.}

¿Defendió San Agustín un primado del amor? La fórmula es muy ambigua y reclama no pocas distinciones antes de contestar. San Agustín opera siempre sobre la base de una dialéctica trinitaria, y sólo dentro de ella puede hablarse de amor y de "primado". Se trata, pues, de metafísica y no de psicología. Se trata de unas potencias que se sumergen en el insconsciente y no de unas potencias del alma, que aparecen tan sólo en la superficie del alma y que se refieren a esa zona consciente en que hablamos de moral, de lógica y de cosmología. Esto significa por de pronto que Agustín y los agustinismos hablan de cosas diferentes. Los Escolásticos suponen que las facultades o potencias del alma son aristotélicas o cartesianas: de ese modo han caído en el lazo tendido por el aristotelismo tradicional. Para ellos un primado de la voluntad significa un primado del amor y un "voluntarismo" característica o aristotélico.

San Agustín no ha caído en ese lazo porque el aristotelismo era para él extraño. Partiendo de una dialéctica trinitaria, la fórmula "primado del amor" querría decir que amamos lo que no conocemos, o que el Espíritu Santo es antes que el Hijo, o que la naturaleza de un ser es antes que su esencia o que su mismo ser, etc. Si los agustinismos no renuncian a ese aristotelismo superficial, esto es, a ese modo superficial de entender a Aristóteles, son extraños a San Agustín; son "agustinistas" en el mismo sentido en que Agustín era "platónico", esto es, a su propio modo o de ningún modo. La primera respuesta será, pues, negativa: Agustín y los agustinismos van aquí por caminos diferentes. En San Agustín no hay ni primado de la voluntad, ni primado del amor. Bien es verdad que tampoco los rivales de estos agustinismos tienen razón, ya que tampoco hay en San Agustín "primado de la razón", por las mismas razones antes apuntadas.

Dentro de un sistema agustiniano, tanto el entendimiento como la 
voluntad proceden de la memoria en sus actividades, pero en un terreno metafísico, inconsciente, no en un terreno psicológico o lógico, al estilo idealista o al estilo científico. Sin embargo, difícilmente se puede hablar de un "primado", como no se puede hablar de un "primado" del Padre sobre el Hijo o sobre el Espíritu Santo. La discusión medieval es, pues, aristotélica, no agustiniana. La memoria, que en el espíritu humano representa al Padre, es el "principio" del espíritu humano; de ella proceden el "verbo" por generación y el "amor" por una procedencia misteriosa que no es generación y que es un grave problema para Agustín ${ }^{32}$.

"Primado del amor" tiene en San Agustín un sentido diferente. $\mathrm{El}$ amor no es ni "antes" ni "mejor" que la verdad: está subordinado a la verdad, pero por eso mismo está ordenado a la verdad, está antes que ella; a la verdad se llega por el amor. Aquí se cambia el orden del proceso: en lugar de ir de arriba abajo, vamos de abajo arriba. En el platonismo hay que preguntarse siempre si se trata de adventu animae o de regressu animae. Si se trata de regreso del alma, el amor está antes de la verdad. El problema primero de la verdad es el amor: hay que ordenar el amor antes de alcanzar la verdad; subimos desde el amor a la verdad.

En cuanto al voluntarismo, hablamos de un voluntarismo romano, en oposición al racionalismo griego. Sólo que la "voluntad" romana no es una facultad o potencia aristotélica, sino una postura integral, personal. En este sentido romano, Agustín es voluntarista, como todos los Padres latinos: afirman la libertad por encima de toda necesidad, de causa formal, de todo naturalismo. Dentro de la dialéctica trinitaria de Agustín, esa "voluntad" corresponde al Padre, no al Espíritu Santo. Es una voluntad imperial, un decreto del Padre, un principio imperial, del que brotan el entendimiento y la voluntad: Deus creavit, quia voluit. Un voluntarismo semejante es diferente del medieval ${ }^{33}$.

32 De Trinit. XV, 25, PL. 42, 1.091 ss.

33. Aparte la "postura" romana, hay en Agustín otro hecho que ha dado pie a un voluntarismo. Al pretender identificar con el anima de los griegos el espíritu judío, hecho a imagen y semejanza de Dios, tiene que forjar una teoría filosófica del "espíritu". Pero por la situación de Agustín, ese "espíritu" tiene que oponerse a la "naturaleza". El "espíritu" no es ya natural, no late en la potencia de la materia, no está sometido a las leyes físicas. En suma, Agustín y el helenismo son incompatibles. Si un agustinismo acepta a Aristóteles, y no le somete previamente a las transformaciones a que sometió Agustín al platonismo, el agustinismo se hace incompatible con San Agustín. Entre el helenismo y el cristianismo hay una incompatibilidad radical, que es preciso reconocer. 
A veces se relaciona el voluntarismo con el "deseo natural de ver a Dios". Pero en un agustinismo, que se inspire realmente en San Agustín, tal deseo ha de ser "natural", esto es, ha de proceder de la naturaleza y no de la voluntad aristotélica: ha de nacer de un "ver a Dios", también natural. Todo será dialéctico y correcto, si se trata de distinguir un modo de ver a Dios de otro modo, pasando por el puente de los deseos naturales; si el hombre ve a Dios, el hombre desea ver a Dios en ese mismo orden. Pero si por deseo entendemos un deseo aristotélico, ahí tenemos adonde fueron a parar los protestantes, Bayo y Jansenio. En suma, sin la mémoria Dei, el deseo natural es inexplicable ${ }^{34}$.

Lo mismo acontece con la delectatio victrix. Por un lado estamos en la metafísica y no en psicología o en moral; por otro lado, la delectatio es fruto de una luz o iluminación, también metafísica. Si no nos situamos en un sistema agustiniano, sino en un aristotelismo tradicional, iremos a parar a un determinismo o a una de esas posturas que lamentamos en Bayo y en los jansenistas. Dígase lo mismo del amorpondus y del voluntate trahor ${ }^{35}$. Hay que evadirse del helenismo enteramente, dominándolo, no rechazándolo; hay que evadirse de todo linaje de naturalismo y situarse en un creacionismo filosófico, además del teológico, para entender bien la dialéctica trinitaria de Agustín e interpretar bien esos problemas que tantas dificultades han creado, por la mixtura de sistemas, por los sincretismos ${ }^{36}$.

Max Scheler proponía la "vuelta a San Agustín", imponiendo un primado del amor. Cometía, sin embargo, una falacia elemental: anteponer a un conocimiento consciente un amor inconsciente: eso es cambiar de orden, metábasis. Es claro que Max Scheler tiene razón: al conocimiento consciente le precede un amor inconsciente. Pero esa razón es falaz: porque al amor inconsciente le precede a su vez un conocimiento inconsciente; y del mismo modo al conocimiento consciente le sigue el amor consciente. El cambio de orden no autoriza a sacar las consecuencias que pretendía sacar Scheler. No se da, pues, un primado del amor ni en el orden consciente ni en el inconsciente. Sin un estudio

34 De Trinit. VIII, 5,8 ss., PL. 42,952 ss.

35 In Jo. 26,3 ss., PL. 34, 1.608.

36 M. GRABMANN, Augustins Lehre vom Glauben und Wissen und ihr Einfluss auf das mittelalterliche Denken (Mittelalterliches Geistesleben, II), München 1936, 36-52. 
de ese amor inconsciente y elemental, habitual, que llamamos memoria, no se puede pensar en un sistema agustiniano ${ }^{37}$.

\section{Primado DE LA gracia.}

A primera vista no se ve por qué un agustinismo ha de sentir recelo hacia el concepto de natura pura, siempre que no se trate de pasar al terreno real, o de convertir las abstracciones en hechos. Agustín acentuó siempre frente a los maniqueos la bondad de toda naturaleza, y consideró el mal como un vitium antinatural. Además, frente al pelagianismo, acentuó la diferencia entre naturaleza y gracia: se le puede considerar como el iniciador, que ha impuesto a la teología posterior ese concepto de natura pura, para evitar toda pretensión pelagiana. Un agustinismo deberá, pues, mirar con benevolencia el concepto de natura pura, mientras sea un concepto.

El que Dios crease a Adán en estado de natura pura o en estado de gracia depende tan sólo de la divina voluntad: la misma natura dependería de la libre voluntad divina. El peligro estaría en salirse del terreno revelado y del terreno existencial para discutir hipótesis y posibilidades: Agustín no especuló, ni le gustaba especular, sobre hipótesis y abstracciones, a no ser en cuanto hipótesis y abstracciones, en cuanto criterios de discusión. El agustinismo, que se compromete en una discusión sobre las condiciones y circunstancias en que Dios pudo o debió crear al hombre, parece excederse y salirse del espúritu agustiniano.

Sin embargo, cuando se reflexiona sobre la historia de la teología, se comprende por qué un agustinismo debe siempre ponerse en guardia frente a toda otra postura que, a su juicio, pueda implicar "naturalismo". Se trata sólo de un recelo polémico, de una postura de defensa, de una precaución. En efecto, Agustín trató de inspirarse cada día más en el espúritu de la Biblia. Y según la Biblia, Adán en su paraíso, era sólo un caso, una aplicación de la teoría israelítica del concepto de gracia. Israel proyecta sobre el primer hombre su propia teología: nada hizo: Adán para merecer el paraíso, como nada hicieron Abrahán, Isaac y Jacob para que se les hicieran promesas. ¿Qué era para Adán el paraíso, sino una promesa? Para los israelitas el paraíso es un futurible. El paraíso

37 M. Scheler, Ordo Amoris, Madrid 1934, 108 ss. Max Scheler llama "ethos" al sistema de estimaciones y preferencias radicales, pero cree que el núcleo más profundo de ese ethos es el ordo amoris. Agustín dice lo contrario: De Trinit. X, 1, 1, PL. 42, 971 ss. 
es el trasunto de Palestina, una proyección ideal y sentimental de los teólogos de Israel. Palestina podía haber sido un paraíso, pues era un futurible, pero terminó siendo una paramera (salsugo) por causa del pecado de Israel. Lo que el agustinismo teme es, pues, el helenismo: una naturaleza autónoma, que exhibe sus derechos, méritos, leyes o exigencias, como si pudiera gloriarse en sí misma, como si tuviese algo que no lo haya recibido. Puesto que el agustinismo tiene de la naturaleza creada ese concepto gracioso y contingente, trata de elevar a la naturaleza mediante la gracia, para que no se convierta en una suerte de materia prima, oscura y abominable.

¿Por qué se ha de acentuar el primado de la gracia frente a la naturaleza? Agustín separó la naturaleza de la gracia ante el ataque dialéctico de Pelagio. El mundo sobrenatural no puede ser una nueva naturaleza, sino un orden diferente, aunque no opuesto, contrapuesto o paralelo. Pero ya se considere la gracia como una nueva "creación", ya se la considere como un auxilio a la naturaleza, la relación entre naturaleza y gracia se hace misteriosa. Agustín trata de mantenerse fiel a la Biblia y especialmente a San Pablo, frente al naturalismo griego. Es claro que, si el hombre nace en pecado y es liberado en el bautismo por un principio nuevo, ese principio ha de ser de orden superior a la naturaleza: de este modo, se nos impone ya un primado de la gracia. Del mismo modo, si la voluntad es impotente para romper sus cadenas, y sobreviene un auxilio que la capacita para sobreponerse a sí misma, es claro también un primado de la gracia en este orden. Mas como esta postura de Agustín ha sido aceptada por todas las escuelas, no se ve claro por qué hemos de hablar de un "agustinismo".

Siempre que se trate de un agustinismo medieval, deberá recordarse que la Escuela de San Víctor inició la serie de los "agustinismos" técnicos, pero lo hizo frente a las posturas que adoptaban los partidarios de una dialéctica que, originada en Boecio, tendía cada día más a convertirse en "pura dialéctica", en lógica. Ahora bien, dada la forzosidad de la dialéctica, se podría desembocar en el naturalismo. Si no desembocaba de hecho, eso se debía a la gran fe y a la santidad de muchos de los Escolásticos. Por eso, todo agustinismo se ve compelido a acentuar también el primado de la gracia, como una precaución necesaria, frente a un naturalismo velado. Acentuar la autonomía de la naturaleza en un creacionismo, o transigir con un naturalismo frente a un Dios creador, resulta una postura curiosa. Si todo procede de la libre voluntad divina, 
como lo admiten las escuelas católicas, sólo cabe que esas escuelas tengan diferente concepto u opinión de lo que es un ser, una esencia, una naturaleza. Por eso, algunas escuelas mantienen una cierta autonomía, un estatuto más o menos autónomo, mientras que el "agustinismo" deberá acentuar la contingencia, disponibilidad, indiferencia y falta de fundamento de las "criaturas". Un agustinismo temerá siempre que Dios se convierta en un Júpiter dominado por la Anánke. De ahí surgirán innumerables y complejas discusiones sobre lo que Dios ha de hacer d.e congruo o de condigno, sobre la deficiencia constitutiva del hombre histórico, sobre la impotencia de la libertad humana después del pecado y sobre tantos otros problemas que el agustinismo contemplará siempre bajo un prisma bíblico y no "filosófico".

El agustinismo parte, pues, siempre de una creación o de un paraíso, si se trata concretamente del hombre. Esto no quiere decir que las demás escuelas católicas no tengan esos mismos puntos de partida. Lo cierto es que se marcan diferencias considerables en estas escuelas católicas. Yo puedo mencionar la creación y el paraíso terrenal, y tratar luego de emancipar todo lo posible al la naturaleza de la acción divina, o al hombre del pecado original; y puedo también hacer todo lo contrario, recordar a cada momento que lo que llamamos naturaleza es la libre voluntad de Dios y que lo que llamamos naturaleza humana es una ruina. el resultado de un pecado original. Además, dentro de esos límites, puedo adoptar posturas extremadas, rigoristas, templadas o conciliadoras. Es claro que el agustinismo se ve obligado aquí a acentuar el primado de la gracia, pues sólo la gracia descubre las posibilidades de salvación. $\mathrm{Si}$ ante un agustinismo colocamos un niño recién nacido, no pensará en una natura pura, sino en un alma poseída por Satanás, a quien hay que aplicar los exorcismos antes de bautizar ${ }^{38}$. Y después del bautismo, seguirá poniéndose en guardia frente a todos aquellos que traten de disimular la presencia activa de ese principio que llamamos "pecado", como si la naturaleza humana fuese simplemente un producto de la naturaleza o de la física. Lejos de emanciparse de la teología, el filósofo

38 Personalmente, tengo que confesar que siempre que he tenido que bautizar a un niño (y en estos últimos años han sido muchas las veces), me da vergüenza pronunciar los exorcismos delante de los padres de la criatura. Las fórmulas de los exorcismos son tan fuertes, tan realistas, tan cortantes, que me causa el mayor asombro el que tantos teólogos hayan protestado contra la Escuela Agustiniana y hayan pasado por alto esos terribles exorcismos. La Iglesia tiene razón y tiene sus razones: pero no estaría mal que los teólogos leyesen despacio esos exorcismos. 
del agustinismo se enfrenta con un hombre que desde su misma raíz es "teológico".

Dígase lo mismo siempre que se trate de las consecuencias del pecado. También aquí el primado de la gracia lo invade todo. La consecuencia primera del pecado fue la ignorancia, el entenebrecimiento, la pérdida de la visión de Dios en el sentido paradisíaco. Por ende, la "gracia" tendrá ante todo carácter de luz o de iluminación. La segunda consecuencia del pecado fue la concupiscencia. De ahí que la gracia tendrá un segundo carácter, que es el de ser "medicina", purificación, caridad, para que se logre la "unidad" del ser humano y con ella la subordinación de los sentidos y potencias a la razón iluminada por la fe y por la gracia.

El hombre medieval, como aparece en Santo Tomás de Aquino, veía las cosas de otro modo: la concupiscencia es acentuada con exceso, y antepuesta a la ignorancia, puesto que el pecado original consiste en un desequilibrio, como un "desorden de apetitos". Este hombre medieval no penetra bien en el espíritu de la Biblia semita, no advierte con claridad que Adán quiso ser igual a Dios, conociendo el bien y el mal. Lo que el Génesis ponía de relieve era un "pecado del entendimiento", la hybris intelectual, una sabiduría que se pronunciaba contra Dios. El castigo debía, pues, corresponder al pecado. En lugar de embeberse en el espíritu de la Biblia, como hacía Agustín, el hombre medieval se embebía en la dialéctica, y los resultados han de ser por fuerza diferentes. De todos modos, el agustinismo trata de fijar aquellos puntos en que Agustín mantiene posturas netas, aunque a veces no sean del todo bien interpretadas. El resultado final es semejante, ya que se impone un primado de la gracia: se profundiza la diferencia entre naturaleza y gracia, y se acentúa la soberanía del orden de la redención, la supresión radical y sistemática del naturalismo y de sus posibles contaminaciones, proclamando en todos los órdenes la soberanía y voluntad libre del Creador y Redentor.

Dentro de la terminología teológica, el orden de la gracia se refiere, más que a una "creación", a una reformación o restauración. Por eso, este orden se atribuye más bien al Hijo, al Redentor. Restaurar significa devolver un objeto a su estado original, devolver una libertad, devolver una visión de Dios, devolver un estado paradisíaco. Y ya que la Biblia no ha hablado con suficiente claridad, los teólogos se han visto precisados a establecer teorías y explicaciones sobre esa restauración o devolución. 
Desde este punto de vista, Agustín se centró en el concepto de "imagen" de Dios. La experiencia le hizo ver la necesidad de distinguir dos imágenes: la natural y la sobrenatural. Esta se perdió con el pecado, y aquélla quedó deteriorada. En el orden nuevo, la sobrenatural ha de ser recobrada y la natural ha de ser restaurada. El primado de la gracia se impone por sí solo.

Sin embargo un agustinismo ha de tener cuidado con poner la gracia "en la sustancia del alma", esto es, no en las facultades aristotélicas del alma, entendimiento y voluntad, como tampoco en una memoria aristotélica. Los místicos, siguiendo a Agustín, hablan de una "centella" que radicaría en la memoria Dei. La gracia será siempre tan gratuita como lo reclama el Antiguo Testamento: un agustinismo no necesita "opio" teológico para matar un poco la sensibilidad de los humanistas. Rechaza las drogas, calmantes y morfinas, prefiriendo mirar de frente al "pecado". Reconoce la grandeza y la potencia de ese pecado. Y por ello reclama ese otro arché victorioso, ese otro principio que viene a imponer su principado en el mundo: la gracia. Igual que en el Paraíso, igual que en Palestina.

\section{Primado de Jesucristo.}

El primado de la gracia implica ya un primado de Jesucristo, fuente de la gracia, Redentor, Restaurador, Reformador. Aparece así en San Agustín una mística de Cristo, en correlación con una mística de Dios. Agustín habría presentado, como San Pablo, una mística de Cristo, afirmando que el hombre no puede unirse directa e inmediatamente con Dios a no ser por medio de Cristo. Incluso los Comentarios a San Juan deberán interpretarse en este sentido, si es correcta la suposición de la necesidad de la mediación de Cristo. Una inhabitación de la Santísima Trinidad en el alma del justo habrá de tener siempre en cuenta que hay que pasar por Cristo. El primado de Jesucristo invadirá de este modo todos los campos de la teología.

La primera consecuencia se referirá a Cristo. No hay unión con Dios ni inhabitación de la Santísima Trinidad, a no ser dentro de un Cuerpo místico de Cristo y por medio de la gracia de Jesucristo. De este modo se opone Agustín a los "místicos" del estilo neoplatónico, que él mismo tuvo que abandonar, y a todos los visionarios que tratan de unirse con Dios directa e inmediatamente. Agustín se habría hecho represen- 
tante de aquella tendencia de la primitiva Cristiandad en que se llamaba al orden a los carismáticos excesivamente individualistas: a Dios no le ha visto nadie ${ }^{39}$; habita en una luz inaccesible, y nadie le ha visto ni puede verlo ${ }^{40}$ : sólo en la vida eterna veremos al Señor cara a cara, pero en este mundo sólo le veremos por espejo y enigma ${ }^{41}$.

La mediación de Cristo se extiende, como es natural, a la Iglesia y al Papa. También aquí ha marcado Agustín un progreso notable en el modo de acentuar la necesidad de estas mediaciones.

El agustinismo ha significado siempre, en la historia de la teología, un fermento de renovación, y por ello es imprescindible su presencia en la crisis teológica que venimos experimentando. De lo contrario, nos debatiremos siempre entre el cielo y la tierra, en el aire, en una zona fácil, pero ilusoria, que no puede salvar al hombre actual, agobiado por tantos problemas reales y dramáticos.

El agustinismo tiene hoy a su disposición muchas ventajas que no pudieron utilizar los antiguos discípulos de San Agustín. La crítica bistórica ha progresado mucho y las ciencias del espíritu permiten contemplar horizontes más profundos en la vida interior. Siempre es muy difícil comprender a San Agustín. Pero creemos que hoy no es tan difícil como en otros tiempos. Un agustinismo deberá volver a su maestro a toda costa, aunque tenga en cuenta que vivimos en el siglo $\mathrm{xx}$ y no en los tiempos del maestro. El espíritu, que edificó el sistema agustiniano, servirá para nuestros tiempos como sirvió para los del Santo. Para levantar un mundo, basta un punto de apoyo.

P. Lope Cilleruelo, O. S. A.

39 Jo. $1,18$.

40 I Tim. 6, 16.

41 I Cor. 13, 12. 